\title{
EI PCE y la huelga general (1958-1967)
}

\author{
Emanuele Treglia \\ Doctorando y Becario de Investigación. Universidad LUISS (Roma) \\ The PCE and the General Strike (1958-1967)
}

\begin{abstract}
RESUMEN ABSTRACT
La Huelga Nacional Pacífica fue unos de los conceptos clave elaborados por el PCE en la fase final del Franquismo, pero los primeros intentos para ponerla en práctica, en 1958 y en 1959, fracasaron. Fue solo en la segunda mitad de los años sesenta cuando los comunistas españoles lograron los primeros resultados significativos en este ámbito: CCOO representaban el instrumento idóneo para realizar la huelga general contra la dictadura.

PALABRAS CLAVE

$P C E$. Comisiones Obreras. Huelga. Antifranquismo. Estudiantes.

The National Pacific Strike was one of the key concepts elaborated by the PCE in the final phase of Francoism, but the first attempts to put it in place, in 1958 and in 1959, were unsuccessful. Only in the late '60s, the Spanish communists achieved meaningful results for the first time: the CCOO represented the appropriate tool to realize the general strike against the dictatorship.

KEY WORDS

PCE. Workers Commissions. Strike. AntiFrancoism. Students
\end{abstract}


La historia del Partido Comunista de España (PCE) de los años cincuenta ha sido caracterizada por la ideación de líneas políticas y de estrategias que fueron desarrolladas y perfeccionadas sólo en el decenio siguiente. Algunos conceptos cuya elaboración había empezado entre el 1954 y el 1958, y que al principio habían logrado resultados mediocres, en efecto produjeron los primeros éxitos desde el 1965-1966. El nacimiento de las Comisiones Obreras, y sus progresiva hegemonización por el PCE, constituyeron el factor clave que permitió a los comunistas corregir algunas carencias del pasado, mejorando tácticas que, hasta entonces, no habían llevado los frutos esperados.

En este ensayo veremos como la idea de la huelga general contra la dictadura franquista, propuesta la primera vez sin éxito por el Partido Comunista en el 1957, luego fue introducida por este en el horizonte teórico del nuevo movimiento obrero, produciendo así los primeros resultados significativos en ocasión de las movilizaciones de enero y de octubre de 1967. Por lo tanto, en las próximas páginas analizaremos en primer lugar el nacimiento del jornadismo en 1958-1959, y los obstáculos y errores que impidieron su éxito; luego pasaremos a ilustrar como la participación en las Comisiones Obreras, y el control que instauraron sobre ellas, permitieron a los comunistas, en la segunda mitad de los años sesenta, perfeccionar el concepto y la práctica de la Huelga General, poniendo así remedio a algunos de los problemas que habían causado el fracaso de la Jornada de Reconciliación Nacional y de la Huelga Nacional Pacífica de la década anterior.

\section{EL NACIMIENTO DEL JORNADISMO}

En el 1956 el Partido Comunista había elaborado los fundamentos teóricos de su Política de Reconciliación Nacional'1 . El problema consistía en encontrar los medios de acción coherentes con lo que esta proponía: o sea, era necesario utilizar métodos que pudieran contar con la participación de la mayoría del pueblo español y que pudieran derrocar al franquismo pacíficamente, sin correr el riesgo de causar una nueva guerra civil ${ }^{2}$. Si, en efecto, el objetivo consistía en favorecer la unidad antifranquista, por lo tanto las iniciativas propuestas por el PCE tenían que perder cualquier carácter sectario, buscando así el apoyo y la colaboración del más amplio número posible de organizaciones y fuerzas político-sociales: para obtener este resultado era indispensable enseñar a los potenciales aliados una cara responsable, y por eso la renuncia a los medios violentos de acción se presentaba como imprescindible. Además, la convicción que la clandestinidad condenase a la impotencia cualquier movimiento revolucionario, llevaba a la conclusión que el nuevo instrumento de lucha debía tener carácter abierto, público, capaz de garantizar la

\footnotetext{
1 Archivo Histórico del Partido Comunista de España (AHPCE), Fondo Documentos, carpeta 37, «Declaración del Partido Comunista de España, junio de 1956. Por la reconciliación nacional, por una solución democrática y pacifica al problema español».

2 SÁNCHEZ RODRÍGUEZ, J.: Teoría y práctica democrática en el PCE, Madrid, FIM, 2004, p. 56.
} 
participación activa de las masas y no sólo de una estrecha vanguardia. Merecen ser tomados en consideración otros dos elementos: la convicción, que tenía raíces profundas en la dirección del Partido, según la cual la mayoría de la población deseaba poner fin a la dictadura, y la idea que ésta se encontrase en un proceso de descomposición irreversible, hacían esperar su caída en cualquier momento. De todas estas premisas, se deducía por lo tanto que lo importante consistía en encontrar un medio capaz de catalizar eficazmente el malcontento general, permitiendo a la crisis latente manifestarse en toda su gravedad y llevando así al derrocamiento del edificio franquista.

En esta óptica el PCE se convenció que una gran movilización de masas, que habría tenido que realizarse contemporáneamente en toda España, constituía un instrumento que respondía perfectamente a todas estas exigencias: una jornada nacional de protesta contra el régimen permitía a todos los ciudadanos manifestar abiertamente, y sin violencia, su rechazo hacia la dictadura, demostrando así que esta no gozaba de ningún apoyo a nivel popular y que, por lo tanto, tenía que rendirse.

Con estas premisas, en septiembre del 1957 el Comité Central del Partido difundió un documento en el cual se proclamaba la necesidad de una Jornada de Reconciliación Nacional. Esta era anunciada y descrita con las siguientes palabras:

«El Partido Comunista propone a todos los españoles, a todos los partidos y grupos políticos y sociales sin distinción la organización de una JORNADA DE RECONCILIACION NACIONAL, contra la carestía, contra la política económica de la dictadura, por la amnistía y por las libertades políticas. Los comunistas no concebimos la JORNADA DE RECONCILIACION NACIONAL como un movimiento subversivo, como la consecuencia de una conspiración, ni como un choque violento contra la dictadura. [...] Los comunistas concebimos la JORNADA DE RECONCILIACION NACIONAL como una movilización pacífica. [...] Dada la imposibilidad, bajo la dictadura, de manifestarse por medio del sufragio, nosotros vemos dicha JORNADA como un amplio y unánime plebiscito nacional, como una advertencia solemne a quienes se obstinan en hacer oídos sordos al malestar de la nación. Vemos esta Jornada como una expresión de los deseos del país de que se produzca un cambio político sin violencia ni derramamiento de sangre» ${ }^{3}$.

La Jornada, por lo tanto, tenía que representar un plebiscito contra Franco, una manifestación de la voluntad popular para poner fin a las estructuras autoritarias. Los mismos comunistas, de toda manera, eran perfectamente conscientes que una sola acción de masas, aunque amplia, no era seguramente suficiente para derrocar al régimen: en este sentido afirmaban que la Jornada casi seguramente no habría sido el «último acto contra la dictadura», pero en cualquier caso habría golpeado duramente al franquismo y habría acelerado su liquidación ${ }^{4}$. A este propósito, la

3 «Resolución del Comité Central sobre la Jornada de Reconciliación Nacional», Mundo Obrero, número extraordinario, septiembre de 1957, p. 2.

4 Ibidem. 
idea a la base del jornadismo suponía que, haciendo coincidir los procesos de oposición en una sola jornada, se iba a acarrear un daño múltiple al régimen, favoreciendo en manera exponencial su descomposición. Si una serie de huelgas parciales podían realizarse contemporáneamente en el mismo día, cada singula acción, que en cada fábrica o taller hubiera carecido de contenido político, produciéndose al unísono con todas las otras, hubiera multiplicado inmediatamente sus efectos ${ }^{5}$.

Por lo que se refiere a la voluntad de colaborar con los otros sectores antifranquistas, se escribía:

«La JORNADA DE RECONCILIACION NACIONAL debe ser una manifestación de unidad de todas las fuerzas político-sociales que desean cambios en la actual situación: debe ser una tarea que asuman en común todos los partidos y grupos sociales desconformes con la dictadura de Francisco Franco. [...] LOS COMUNISTAS CONCEBIMOS ESTA JORNADA COMO LA COINCIDENCIA DE CATOLICOS, DEMOCRATAS CRISTIANOS DE DIVERSA TENDENCIA, MONARQUICOS, LIBERALES, REPUBLICANOS, NACIONALISTAS, SOCIALISTAS, CENETISTAS Y COMUNISTAS. [...] Esta concepción muestra, por su amplitud, cuán lejos está del ánimo de los comunistas de hacer de dicha JORNADA un acto subversivo, violento o revanchista. Depende de la actitud de cada una de las fuerzas citadas el que la JORNADA sea efectivamente una reafirmación de los españoles y de su voluntad de cambio pacífico» ${ }^{6}$.

Para obtener dicha unidad antifranquista, el PCE empezó a enviar propuestas de colaboración a las direcciones de las otras fuerzas, en especial modo al PSOE, y a difundir continuamente declaraciones en las cuales se afirmaba la necesidad de preparar la movilización conjuntamente, llegando a un acuerdo de acción común 7 .

La Jornada de Reconciliación Nacional tuvo lugar el 5 de mayo de 1958, pero fue un fracaso total. En efecto ninguna de las otras fuerzas de oposición participó, y por lo tanto el Partido Comunista tuvo que afrontarla prácticamente solo ${ }^{8}$. Son dos las principales causas que explican la falta de éxito de la iniciativa: el anticomunismo y la despolitización de las masas españolas. Por lo que se refiere al primer factor, hay que subrayar que, desde el final de la guerra civil, el PCE estaba sometido a un régimen de exclusión sistemática por parte de todas las otras organizaciones de la oposición: esta situación determinó que, a pesar de todos los esfuerzos que los comunistas habían hecho para establecer contactos con los otros partidos para organizar juntos la Jornada, las otras fuerzas rechazaron com-

${ }^{5}$ MORÁN, G.: Miseria y grandeza del Partido Comunista de España, Barcelona, Planeta, 1986, p. 313.

6 «Resolución del Comité Central sobre la Jornada de Reconciliación Nacional», Ob. cit., p. 2.

7 Ver, por ejemplo: AHPCE, Fondo Documentos, carpeta 38, «Manifiesto del Partido Comunista en el primero de mayo», abril de 1958, y AHPCE, Fondo Documentos, carpeta 38, «III Pleno del Comité Central del Partido Comunista de España», septiembre de 1957, pp. 119-121.

8 BABIANO, J.: «La política de reconciliación nacional y sus repercusiones en el movimiento obrero (breves notas)», en VV.AA.: «Estrategias de alianza y políticas unitarias en la Historia del PCE», Papeles de la FIM, número 24, edición electrónica, FIM, 2006. 
pletamente dicha propuesta. En la declaración difundida por la dirección del PCE en los días sucesivos a la realización de la movilización, a este propósito se constataba:

«A partir de septiembre de 1957, la dirección del Partido Comunista se puso en relación con los dirigentes de diversas fuerzas políticas, sometiendo a su consideración la iniciativa de una Jornada de Reconciliación Nacional, con la voluntad de admitir cuantas sugerencias y proposiciones de carácter positivo se nos hiciesen. Pero ninguna de las direcciones de esas fuerzas -PSOE, Demócratas Cristianos, Cenetistas, Nacionalistas Vascos, Republicanos, Liberales- acepto tomar posición pública en favor de dicha acción y realizar una actividad práctica para organizarla»`9 .

El anticomunismo no caracterizaba sólo las direcciones de los partidos, sino también las masas populares, e iba a unirse a su substancial despolitización ${ }^{10}$ : esta tenía sus raíces en parte en la naturaleza paternalista-autoritaria del régimen, y en parte en el miedo de la represión realizada por el aparato franquista ${ }^{11}$. El conjunto de estos factores ayuda a comprender por qué en la movilización del 5 de mayo tomaron parte exclusivamente los militantes comunistas, con el pequeño apoyo del Frente de Liberación Popular.

A pesar de todo, el PCE expresó una valoración triunfalista de la Jornada, definiéndola como una gran manifestación popular contra la dictadura del general Franco, a la cual habían participado millones de españoles ${ }^{12}$. En Nuestra Bandera Dolores Ibárruri escribía:

«La Jornada de reconciliación nacional celebrada el cinco de Mayo [...] ha mostrado, en su organización y desarrollo, al mismo tiempo que la debilidad del régimen, las enormes posibilidades que existen en el país para una lucha de masas de carácter nacional contra la dictadura. [...] Ella ha constituido un gran éxito, porque respondía al sentimiento antifranquista que late en la conciencia popular y que en la jornada ha encontrado su expresión más viva»13.

9 AHPCE, Fondo Documentos, carpeta 39, «Declaración del Partido Comunista de España sobre la Jornada de Reconciliación Nacional», p. 2. 179.

10 CARR, R., y FUSI, J. P.: España, de la dictadura a la democracia, Barcelona, Planeta, 1979, p.

11 «La situación económica era tan difícil en los últimos cincuenta [...] que la dirección comunista creyó que el estallido social era probable, olvidando o minusvalorando el grado de desarticulación social que había conseguido la dictadura y el miedo extendido entre los trabajadores a las consecuencias de las protestas reivindicativas», en MOLINERO, C., y YSÁS, P.: «El Partido del antifranquismo (1956-1977)», en Actas del I Congreso sobre la Historia del PCE. 1920-1977. Oviedo 6, 7 y 8 de mayo de 2004, edición electrónica, FIM, 2004. Ver también BABIANO, J., Ob. cit.

12 «Declaración del Partido Comunista de España sobre la Jornada de Reconciliación Nacional», Op. cit., p.2. Ver también «Resumen de las deliberaciones del IV Pleno de Nuestro Comité Central», Nuestra Bandera, número 22, octubre de 1958, y AHPCE, Fondo Documentos, carpeta 39, «Declaración del P.C de Euzkadi. El pueblo Vasco ha participado ampliamente en la Jornada de Reconciliación Nacional».

13 IBÁRRURI, D.: «Un plebiscito nacional contra la dictadura franquista», Nuestra Bandera, número 21, julio de 1958, pp. 8-9. 


\section{La Huelga Nacional Pacífica}

A pesar del fracaso de la acción del 5 de mayo, un año después el PCE, empujado también por la confianza que le inspiraba la oleada de manifestaciones que estaba produciéndose en el país, convocó una otra manifestación análoga: la Huelga Nacional Pacífica, que tuvo lugar el 18 de junio de 1959. Ésta era concebida por el Partido como una acción conjunta del pueblo, o sea de los obreros, de los campesinos, de la pequeña burguesía, de los funcionarios, de los intelectuales, de los comerciantes, con el apoyo o por lo menos con la neutralidad de las fuerzas armadas, contra la dictadura ${ }^{14}$. De esta movilización, así como de aquella del 5 de mayo, se subrayaba su carácter pacífico y de masa.

EI PCE de esta manera se movía de la idea de la Jornada de Reconciliación Nacional para llegar a otra que, aunque no fuese muy diferente que la anterior, se acercaba más explícitamente al concepto de huelga general que tenía profundas raíces en la tradición del sindicalismo revolucionario teorizado por Sorel entre los siglos XIX y XX' ${ }^{15}$ : el medio con el cual dar inicio al cambio social era indicado por la suspensión colectiva del trabajo, considerada capaz de provocar la explosión de las contradicciones internas al sistema vigente. Tanto para los comunistas españoles como para los partidarios de las idea sorelianas, «el aspecto más importante de la huelga general era su papel movilizador, su capacidad de galvanizar energías e inspirar la acción, el instrumento mediante el cual la participación de las masas transforma la realidad ${ }^{16}$. A pesar de las semejanzas, de toda manera habían «enormes diferencias que separaban la línea política del PCE de la del sindicalismo revolucionario de principios de siglo. [...] Los fines que se persiguen con ella son diferentes: para los sindicalistas se trataba de un hecho que abría las puertas a la revolución social, en tanto que para los comunistas españoles era el medio de acabar con la dictadura y, además, no era una acción exclusiva del proletariado y por ello se convertía en huelga nacional» ${ }^{17}$.

El Partido Comunista, en línea con lo que proponía con su Política de Reconciliación Nacional, quería mostrar su rostro moderado, y por lo tanto había dejado de lado los rasgos más explícitamente revolucionarios. En este sentido, la huelga general no era considerada como un instrumento mediante el cual poner en marcha un cambio global, un vuelco de la sociedad capitalista en su conjunto, dado que una tal concepción habría alejado las capas medias e impedido la formación de cualquiera alianza amplia: en cambio era concebida como un medio de acción para acelerar y llevar hasta las consecuencias más extremas la crisis del régimen franquista, provocando pacíficamente su caída y empezando así la transición hacia

14 AHPCE, Fondo Documentos, carpeta 40, «Por una Huelga General Pacífica Nacional de 24 horas contra la dictadura», 1959.

15 SOREL, G.: Riflessioni sulla violenza, Milano, Rizzoli, 1997.

16 SÁNCHEZ RODRÍGUEZ, J.: Ob. cit., p. 60.

17 Ibidem. 
una democracia parlamentaria de tipo occidental. La elección del nombre, en este sentido, no era casual: con esto, en efecto, se ponía en evidencia que la movilización, además que pacífica, tenía que ser nacional, o sea contar con el apoyo y con la participación no solo del proletariado, sino de los españoles de todas las capas sociales que, sobrepasando las líneas divisorias de la guerra civil, tenían que unirse en la oposición a la dictadura.

La movilización del 18 de julio de 1959, así como la Jornada de Reconciliación Nacional del año precedente, fue un fracaso. En efecto se reprodujeron los mismos e idénticos problemas: tampoco en esta ocasión el PCE encontró aliados significativos $^{18}$, y por lo tanto a la huelga adhirieron solo sus militantes y los de algunos pequeños grupos. De toda manera la dirección del Partido, aunque admitía que la acción no había alcanzado las proporciones esperadas, también en este caso disimuló la realidad, declarando: «Este aparente fracaso ha sido un paso de siete leguas hacia la liquidación de la dictadura del general Franco» ${ }^{19}$.

El convocar jornadas como las del 5 de mayo y del 18 de junio, para el PCE respondía a una lógica precisa: «poner en tensión la parte más dinámica del antifranquismo ${ }^{20}$. Por eso era necesario negar los fracasos y describirlos como triunfos, para infundir confianza en sus activistas y, al mismo tiempo, ejercitar capacidad de atracción sobre nuevos elementos. En este sentido se puede afirmar que la política del Partido Comunista pecaba de un profundo voluntarismo o subjetivismo: o sea presentaba un análisis de la realidad que tenía en cuenta solo los aspectos positivos descartando los negativos ${ }^{21}$. Por eso se actuaba siguiendo una línea que Víctor Alba sintetiza con estas palabras: «si para que la gente luche hay que engañar, se engaña; y para que luche, la gente ha de ver la victoria al alcance de la mano ${ }^{22}$. Pero la dirección, poniendo al lado la retórica, era perfectamente consciente de los problemas que habían determinado el fracaso de la Jornada de Reconciliación Nacional y de la Huelga Nacional Pacífica: por lo tanto esperó años antes de intentar otras acciones análogas. $O$ sea, esperó que se presentasen las condiciones favorables para poner remedio a las carencias del pasado.

18 Por lo que se refiere al intento del PCE para establecer contactos con las otras fuerzas socio-política ver «Que las direcciones de los partidos antifranquistas se pronuncien por la huelga nacional», Mundo Obrero, número 11, abril de 1959. Para el rechazo de dicha colaboración por parte del PSOE consultar AHPCE, Fondo Documentos, carpeta 40, «A la Comisión Ejecutiva del Partido Socialista Obrero Español», junio de 1959. Ver también VALVERDE MÁRQUEZ, M. J.: «EI PCE y la llamada a la unidad de acción con el PSOE (1956-1959)», en Actas del I Congreso... cit.

19 AHPCE, Documentos, carpeta 40, «Declaración del Partido Comunista de España sobre la Huelga Nacional», julio de 1959, p. 1.

20 MOLINERO, C., y YSÁS, P.: Ob. cit.

21 MORÁN, G.: Op. cit., p. 313. Hay que subrayar que la crítica al voluntarismo de la dirección del PCE fue uno de los puntos clave de la divergencia que en el 1964 determinó la expulsión de Claudín y Semprún. Ver CLAUDíN, F.: Documentos de una divergencia comunista, Barcelona, 1978.

22 ALBA, V.: El Partido Comunista en España, Barcelona, Planeta, 1979, p. 315. 


\section{LAS COMISIONES Y EL 1967}

La Huelga Nacional Pacífica fue unos de los conceptos claves elaborados por el PCE, y formó parte de su discurso político y de su estrategia hasta la desaparición de la dictadura, sin que llegase a cumplir la función que se le había asignado.

En la primera mitad de los años sesenta el Partido declaró muchas veces, sobre todo en ocasión de la oleada de movilizaciones del 1962-1964, que se estaba avanzando hacía la Huelga Nacional ${ }^{23}$. Pero fue solo cuando logró hegemonizar el nuevo movimiento obrero ${ }^{24}$, y dotarlo de una estructura suficientemente estable con las elecciones sindicales del $1966^{25}$, que creyó poseer finalmente el instrumento idóneo para alcanzar este objetivo. Las Comisiones Obreras, en efecto, presentaban caracteres que permitían superar los obstáculos que habían impedido el éxito del jornadismo originario. En primer lugar los militantes del PCE en su interior, trabajando cada día al lado de miembros de otras fuerzas o de elementos apolíticos, tenían la posibilidad de estrechar con estos «alianzas de hecho», sobrepasando así el difícil camino de los acuerdos formales entre las diferentes organizaciones. Los comunistas, por lo tanto, llevaron a un nivel superior la unidad que se producía diariamente entre los obreros de las diferentes tendencias cuando llevaban adelante las reivindicaciones en cada fábrica: es decir que incluyeron esta unidad de base en una línea socio-política más amplia, la cual tenía como medio de acción decisivo la huelga general. El control de las Comisiones daba al PCE otra ventaja fundamental: mediante ellas, y escondiéndose detrás de su teórica apoliticidad, podía convocar movilizaciones sin aparecer como el organizador principal, de manera que el anticomunismo no impidiera una adhesión de masa. Hay que considerar, además, que en ocasión de la Jornada de Reconciliación Nacional el Partido había lamentado la ausencia de un organismo de coordinación en el cual confluyesen todas las fuerzas de oposición ${ }^{26}$ : pero en la segunda mitad de los sesenta este organismo podía ser representado por las Comisiones Obreras. En fin, no hay que olvidar que el nivel de conflictividad de la sociedad española en el 1966-1967

23 Ibidem.

24 Las Comisiones Obreras, nacidas en la segunda mitad de los cincuenta como expresión espontánea de los trabajadores de las diferentes familias ideológicas, a partir del 1962-1964 empezaron a ser hegemonizadas por el PCE. El control de los comunistas sobre este nuevo fenómeno se consolidó a partir del 1966. Ver, entre los otros, ARIZA, J.: Comisiones Obreras, Madrid, Avance/Mañana Editoriales, 1976, MARAVALL, J. M.: Dictadura y disentimiento político. Obreros y estudiantes bajo el franquismo, Ediciones Alfaguara, RUÍZ, D., (coordinador): Historia de Comisiones Obreras (1958-1988), Madrid, Siglo XXI de España Editores, 1993, SARTORIUS, N.: El resurgir del movimiento obrero, Barcelona, Laia, 1975, SARTORIUS, N.: El sindicalismo de nuevo tipo. Ensayos sobre Comisiones Obreras, Barcelona, Laia, 1977, DÍAZ, J. A.: Luchas internas en Comisiones Obreras (Barcelona, 1964-1970), Barcelona, 1977, VEGA GARCÍA, R.: Las huelgas de 1962: hay una luz en Asturias, Fundación Juan Muñiz Zapico, 2002,

25 Ver MATEOS, A.: «Comunistas, socialistas y sindicalistas ante las elecciones del Sindicato Vertical, 1944-1967», en Espacio, Tiempo y Forma, número 1, Madrid, UNED, 1987.

26 IZCARAY, J.: «Hacia una gran Jornada de Reconciliación Nacional», Mundo Obrero, número 14, septiembre de 1957. 
superaba significativamente lo del decenio precedente: la oposición al régimen franquista había alcanzado proporciones considerables, y el nuevo movimiento obrero se demostraba capaz de poner en marcha sus iniciativas con un número de personas inimaginable para el 1958-1959.

El conjunto de estos factores llevaba el PCE a creer que el fatídico día de la huelga general estaba acercándose.

\section{El 27 de octubre}

Al principio de enero del 1967 las Comisiones Obreras de Madrid convocaron una movilización para el 27 del mismo mes. Las razones de esta acción eran múltiples: algunas de carácter más inmediato, como la protesta contra los despidos y contra la subida de los precios, y otras que presentaban un contenido más explícitamente político, como la crítica a la OSE y la lucha para las libertades sindicales. Expuestas tales motivaciones, en el documento de convocatoria las Comisiones madrileñas seguían declarando:

«Ante esta situación creemos que ha llegado el momento de hacer frente una vez más a los males que nos aquejan con una acción que, sin ser definitiva, sirva de seria advertencia para todos de la voluntad y capacidad de resistencia de los obreros madrileños. Para ello os llamamos a una acción concreta, para que el día 27 de enero realicemos en cada empresa, taller o centro de trabajo, una acción demostrativa, como paro parcial o simbólico, trabajo lento, [...] cartas colectivas de protesta a la prensa o autoridades sobre la carestía de la vida y otros problemas obreros, etc. [...] Como acción conjunta y solidaria boicoteemos los transportes a partir de las tres de la tarde, a la salida del trabajo, marchando a pie [...] hasta el centro de la ciudad [...] para después disolvernos pacíficamente»27.

Esta movilización, preparada en poco tiempo y concebida no como una huelga general, sino como un conjunto de diferentes tipos de acciones de protesta, obtuvo un número de adhesiones superior a las expectativas ${ }^{28}$. Este resultado se presentaba como una confirma de la capacidad del nuevo movimiento obrero para realizar iniciativas que gozasen de un amplio apoyo por las masas. Por eso el PCE se convenció que, utilizando el prestigio y el carácter abierto de las Comisiones, era posible convocar una nueva jornada de manifestaciones, organizada con más tiempo y atención que la del 27 de enero: una nueva jornada de lucha que podía representar un ensayo de las fuerzas del nuevo movimiento obrero, para dar un duro golpe al poder franquista y avanzar significativamente hacia la huelga nacional29. Así, después de ocho años, renacía el jornadismo y tomaba nuevamente cuerpo la idea de la huelga nacional pacífica contra la dictadura. Este proyecto,

27 «Las C.O. de Madrid llaman a los trabajadores a realizar una acción demostrativa en cada lugar de trabajo», Mundo Obrero, número 5, enero de 1967, p. 1.

28 «Más de 100.000 manifestantes el 27 de enero en Madrid», Mundo Obrero, número 6, febrero de 1967, p. 1.

29 AHPCE, Fondo Documentos, Plenos, «Reunión del C.C. 16-9-1967», p. 22. 
consideradas las proporciones alcanzadas por las Comisiones, era considerado, quizás por la primera vez, como un objetivo realmente realizable, y la nueva movilización tenía que constituir su prueba general.

La nueva jornada fue convocada para el 27 de octubre ${ }^{30}$, y esta vez la iniciativa fue extendida a todas las principales ciudades españolas ${ }^{31}$. EI PCE, analizando los errores cometidos en ocasión del jornadismo originario, se había dado cuenta que uno de estos había sido la falta de organización. Sobre Nuestra Bandera, por ejemplo, García escribió: «Una de las enseñanzas más importantes que nos brindó la huelga del 18 de junio fue que la organización de los trabajadores era insuficiente para lograr el éxito de la huelga» ${ }^{32}$. Por lo tanto, para poner remedio a las carencias del pasado, en una reunión que tuvo lugar en el septiembre del 1967, el Comité Central del Partido declaraba la necesidad de preparar dicha acción en las asambleas, con un trabajo abierto, de manera que las masas podían sentirse como parte activa de la iniciativa en cada fase ${ }^{33}$. Si la Jornada de Reconciliación Nacional y la Huelga General Pacífica habían sido preparadas solo por el núcleo dirigente del PCE, y por esto los obreros las habían percibido como ajenas, ahora se utilizaban las asambleas y la discusión común para favorecer la participación de todos los trabajadores, de manera que estos percibiesen la manifestación como verdaderamente suya ${ }^{34}$. Carrillo a este propósito escribió: «Para movilizar a las amplias masas no bastan las hojas, la agitación escrita; no bastan las decisiones tomadas por un grupo de vanguardia por prestigioso que sea. Hace falta que las masas mismas se sientan partícipes de la iniciativa y asuman conscientemente su responsabilidad ${ }^{35}$. Hay que subrayar, además, que el PCE recomendaba a sus militantes disimular el papel hegemónico y el control que ejercitaba sobre las Comisiones, para evitar que la movilización de octubre fuese percibida como una iniciativa comunista ${ }^{36}$ : en efecto en caso contrario muchos sectores de la oposición se habrían alejado, reproduciendo la misma situación de aislamiento en la cual el Partido tuvo que afrontar las jornadas del 5 de mayo y del 18 de junio. Los comunistas, por lo tanto, intentaban utilizar el carácter abierto y pluralista del nuevo movimiento obrero para garantizar una adhesión masiva a un proyecto que estaban intentando realizar desde un decenio.

30 «Las C. O. de Madrid convocan a importantes acciones el 27 de Octubre», Mundo Obrero, número 21, octubre de 1967, pp. 1-2.

${ }^{31}$ Ver, por ejemplo, «Manifiesto de las C. O. de Cataluña ante la jornada del 27 de Octubre», Mundo Obrero, número 21 , octubre de 1967, p. 3.

32 GARCÍA, E.: «La organización de las masas», Nuestra Bandera, número 27, julio 1960, p. 21. Ver también AHPCE, Fondo Documentos, carpeta 40, «Declaración del Partido Comunista de España sobre la Huelga Nacional», agosto 1959, p. 13.

${ }^{33}$ AHPCE, Fondo Documentos, Plenos, «Reunión del C.C. 16-9-1967», p. 24. Ver también AHPCE, Fondo Movimiento Obrero, caja 85 , carpeta 1/2.1, «Informe de la reunión celebrada el día 8 de octubre de 1967, Barcelona».

34 VEGA GARCÍA, R.: «La relación con Comisiones Obreras», en VV.AA., Estrategias de alianza y políticas unitarias en la Historia del PCE, cit.

35 CARRILLO, S.: «Algunas enseñanzas de la jornada del 27 de Octubre», Nuestra Bandera, número 56-57, 1968, pp. 18-19.

36 AHPCE, Fondo Documentos, Plenos, «Reunión del C.C. 16-9-1967», p. 24. 
La acción del 27 de octubre, preparada con centenas de asambleas, en Madrid se desarrolló con la misma dinámica de la de enero (trabajo lento, envío de cartas de protesta a la prensa, marcha hacia el centro de la ciudad etc.), y contó en la adhesión de más de 150.000 personas. También en las otras ciudades la iniciativa obtuvo éxito, aunque en proporción menor respecto a la capital ${ }^{37}$. Considerados los resultados, el PCE no dudaba declarar que la del 27 de octubre había sido «la acción más extraordinaria del proletariado»38 desde el 1936.

Dejando al lado las exageraciones, de toda manera no cabe duda que el buen éxito de la manifestación representaba un resultado de importancia fundamental por diversas razones. En primer lugar había determinado la «consagración de las Comisiones Obreras como la forma de unidad, organización y lucha de los trabajadores "39: una legitimación que, aunque ya en parte se había obtenido con las elecciones sindicales del 1966, faltaba todavía una demostración práctica mediante la cual poner a la prueba la concreta capacidad de movilización del nuevo movimiento obrero. Otro importante aspecto de la jornada del 27 de octubre era que el Partido Comunista había podido testar un punto clave de su estrategia sindical-política: había averiguado que el utilizo de las Comisiones como medio mediante el cual convocar y organizar acciones de masas, sin aparecer en primera persona como su verdadero promotor, permitía conseguir el apoyo y la participación de amplios sectores de la sociedad española, alejando así el riesgo del aislamiento. EI PCE además creía que los acontecimientos del 27 de octubre habían representado un decisivo paso adelante hacia la huelga general, y demostrado que esta podía transformarse en una posibilidad concreta ${ }^{40}$. A este propósito Santiago Carrillo declaró: «A través de luchas como éstas se van preparando en España el ambiente y las condiciones para llegar en su día a la huelga general» ${ }^{41}$.

\section{Partido, Comisiones y estudiantes}

El movimiento obrero y el estudiantil constituyeron, desde la segunda mitad de los años cincuenta, las dos fuerzas principales de la oposición al franquismo ${ }^{42}$. Luchaban para los mismos objetivos: en primer lugar para obtener la libertad sindical cada uno en su respectivo campo y, en una perspectiva de más largo plazo, para derrocar la dictadura. El desarrollo de formas de colaboración entre los dos parecía

37 Para una panorámica general ver «Crónica de lo que fue el 27 de octubre», Nuestra Bandera, número 56-57, 1968, pp. 27-60. Ver también «El 27 de octubre en Madrid y El 27 de octubre en provincias», Mundo Obrero, número 22, noviembre de 1967, p. 5.

38 «Declaraciones de S. Carrillo tras la jornada del 27 de octubre», Mundo Obrero, número 22, noviembre de 1967, p. 1.

39 CARRILLO, S.: «Algunas enseñanzas...», cit., p. 17.

40 Idem, p. 15.

41 «Declaraciones de S. Carrillo tras la jornada del 27 de octubre», Mundo Obrero, número 22, noviembre de 1967, p. 2.

42 Sobre las movilizaciones estudiantiles ver MARAVALL, J. M.: Ob. cit., LIZCANO, P.: La generación del 56: la universidad contra Franco, Grijalbo, 1981, VALDEVIRA, G.: La oposición estudiantil al franquismo, Madrid, Editorial Síntesis, 2006. 
como natural: el PCE, por lo tanto, en la segunda mitad de los sesenta intentó utilizar a las Comisiones como instrumento mediante el cual obtener la participación de los estudiantes para la futura huelga general. Fue en el año 1967 en que los dos movimientos sociales antifranquistas más importantes empezaron a coordinarse en la lucha contra la represión y para las libertades democráticas ${ }^{43}$. En efecto en ocasión de las jornadas del 27 de enero y del 27 de octubre los estudiantes solidarizaron con los obreros, realizando asambleas y manifestaciones al interno de las facultades, y participando activamente a las acciones en las calles. En las universidades habían numerosos carteles donde se podían leer eslogan como: "Comisiones Obreras ¡si! Franco ¡no!», y «iObreros y estudiantes unidos! »44.

EI PCE, por su parte, juzgaba esta unidad de acción como «fecunda de promesas para el porvenir de España» ${ }^{45}$, y proponía empezar dicha colaboración a partir de las reivindicaciones inmediatas (esencialmente la libertad sindical tanto para los estudiantes cuanto para los trabajadores), y luego elaborar plataformas de acuerdos para avanzar juntos hacia el gran objetivo común: la democratización de la sociedad española, la cual tenía que obtenerse mediante la acción decisiva de la Huelga Nacional Política. A este propósito, ya en el 1960 una relación del Comité Central declaraba: «Los estudiantes pueden desempeñar un papel muy importante en la preparación y realización de la huelga nacional, asegurándola en los centros de enseñanza, y en las manifestaciones de calle ${ }^{46}$. El Partido Comunista por lo tanto intentaba establecer un contacto y un diálogo duradero entre las Comisiones y el Sindicato Democrático de los Estudiantes, para asegurarse la participación activa de la oposición universitaria a la movilización definitiva contra la dictadura.

Hay que subrayar que no sólo los estudiantes, sino también una parte considerable de los intelectuales españoles empezaron a fraternizar con los obreros. En ocasión de las movilizaciones del 1967 en efecto muchos intelectuales manifestaron abiertamente su apoyo a las acciones de las Comisiones ${ }^{47} \mathrm{y}$, en abril, en 565 enviaron una carta a Agustín Muños Grandes, el Vicepresidente del Gobierno, en la cual reclamaban libertad de reunión y de expresión y, más en general, las libertades políticas ${ }^{48}$.

EI PCE, por lo tanto, afirmaba la necesidad de dotar de mayor estabilidad y oficialidad estas relaciones informales entre obreros, estudiantes e intelectuales, de

43 VALDEVIRA, G.: Op. cit., p. 94.

44 «La Universidad contra la dictadura», Mundo Obrero, número 10, abril de 1967, p. 8, VALDEVIRA, G.: Ob. cit., p. 95, AHPCE, Fondo Movimiento Obrero, «Reunión celebrada el dìa 3-2-1967», p. 1, Díaz, J., «Diagnostico de la Universidad y otras cosas», Nuestra Bandera, número 56-57, 1968, p. 64.

45 «La libertad es indivisible», Mundo Obrero, número 6, febrero de 1967, p. 1.

46 AHPCE, Fondo Documentos, carpeta 41, «A los Comités del Partido. Informe del CE del PCE», agosto 1960, p. 9.

47 «Sobre los actuales movimientos de intelectuales, profesionales y artistas», Nuestra Bandera, número 54, 1967, pp. 152-153.

48 «565 intelectuales reclaman las libertades sindicales y políticas», Mundo Obrero, número 9, marzo de 1967, p. 1. EI PCE definió esta carta como «documento de gran alcance político y humano», en Nuestra Bandera, número 54, 1967, p. 153. 
manera que todos estos diferentes movimientos pudiesen colaborar eficazmente para la realización de la Huelga Nacional Pacífica. El concepto elaborado por el Partido para satisfacer esta exigencia tomó el nombre de Alianza de las Fuerzas del Trabajo y de la Cultura ${ }^{49}$. Ésta podía favorecer la realización de la huelga general ${ }^{50}$, siendo una plataforma común, un lugar de encuentro y diálogo, un organismo de unión y coordinación general entre los diferentes movimientos, partidos y capas sociales españolas: esto habría permitido que dicha decisiva acción no fuese una iniciativa de la sola clase obrera, sino del conjunto de los ciudadanos, tomando así un verdadero carácter nacional. En este marco, el PCE habría tenido que utilizar a las Comisiones como fundamental instrumento mediante el cual relacionarse con el Sindicato Democrático de los Estudiantes y con las demás fuerzas antifranquistas. De toda manera hay que subrayar que el Partido en dicha Alianza no quería ponerse en una situación de paridad con los otros grupos: miraba a desempeñar un papel "no dirigente, sino dominante ${ }^{51}$. Dicho en otras palabras, quería servirse del control que ejercitaba sobre el nuevo movimiento obrero para imponer su estrategia a las otras organizaciones, escondiéndose detrás del supuesto carácter pluralista y abierto de las Comisiones.

Lo de la Alianza de las Fuerzas del Trabajo y de la Cultura fue un concepto que, junto a lo de la huelga general de la cual tenía que favorecer la realización, ocupó una posición clave en la teoría y en la práctica del PCE hasta la desaparición de la dictadura.

\section{La atención a las fuerzas armadas}

Ahora hay que abrir un paréntesis, para ilustrar otro elemento clave en la teorización comunista de la huelga general. Ésta no habría podido tener carácter pacífico si las fuerzas armadas hubiesen reaccionado con violencia a las manifestaciones populares. Por lo tanto desde la segunda mitad de los años cincuenta el PCE, en el marco de su Política de Reconciliación Nacional, intentó realizar una

49 Carrillo escribía: «La concepción leninista de la alianza de los obreros y campesinos continúa siendo justa. [...] Pero, particularmente en los países desarrollados o en desarrollo, la nueva situación social de las fuerzas de la cultura reclama una amplificación de esa alianza de los obreros y los campesinos hacia los intelectuales y estudiantes. Es decir, hoy, la realización de la revolución pone al orden del día la necesidad de forjar lo que los comunistas españoles hemos denominado la alianza de las fuerzas del Trabajo y de la Cultura», en CARRILLO, S.: La lucha por el socialismo, hoy, suplemento a Nuestra Bandera, número 58, junio de 1968, pp. 15-16.

50 CARRILLO, S.: Nuevos enfoques a problemas de hoy, Paris, Editions Sociales, 1967, p. 92.

51 Idem, p. 180. Sobre la diferencia entre papel dirigente y papel dominante Sartorius escribió: «No es lo mismo, pues, dominar que dirigir $\mathrm{n}$ movimiento, un Estado, etc. En el primer caso se establece entre el partido o los partidos [...] y las instituciones de que se trate una conexión mecánica, burocrática, muerta; en el segundo, una relación dinámica, democrática, viva», en SARTORIUS, N.: El sindicalismo de nuevo tipo. Ensayos..., p. 135. La diferencia, por lo tanto, era sutil: mientras que en el caso del papel dominante la línea decidida por los comunistas era impuesta automáticamente sin admitir discusiones al respecto, definiéndose dirigente el Partido no renunciaba a su tarea de «iluminar a las masas» y de guiarlas, pero mientras que lo hacía intentaba hacerlas participes del desarrollo de sus orientaciones. 
estrategia de acercamiento al ejército y a todas las fuerzas de orden público, para garantizarse su apoyo, o por lo menos su neutralidad, en ocasión de la acción definitiva contra la dictadura.

El punto de partida consistía en la consideración que las estructuras militares españolas, como cualquiera otra institución franquista, se encontraban en una situación de profunda crisis. A este propósito el Comité Central del Partido afirmaba: «La realidad es que el Ejército español se encuentra desunido y descontento. [...] Se trata de un sentimiento difuso de irritación y de descontento. [...] Un sentimiento que, ciertamente, no lleva todavía a la insubordinación, pero que, con el tiempo y con la agravación de la situación, puede conducir hasta ella»52.

Los comunistas además creían que un número cada vez más alto de los miembros de las fuerzas armadas estaban convenciéndose de la necesidad de un cambio democrático ${ }^{53}$. La cosa importante, por lo tanto, consistía en el fomentar este malestar, y al mismo tiempo asegurar a los militares que el conflicto pueblodictadura no correspondía a un conflicto pueblo-ejército. Por eso sobre Mundo Obrero se escribía:

«Los trabajadores no somos antimilitaristas. Comprendemos que mientras todos los países no lleguen a un acuerdo de desarme general, los ejércitos son una necesidad. [...] Estimamos, también, que el Ejército para que sea respetado por el pueblo debe de colocarse en el marco exclusivo de la defensa nacional, no aceptar misiones de represión interna y salvaguardar así su carácter de institución patriótica defensiva por encima de los designios temporales de un régimen cuyas formas y estructuras todo el mundo coincide que es necesario transformar» ${ }^{54}$.

Dadas estas premisas, el Partido Comunista miraba a obtener una adhesión de las fuerzas armadas a la Huelga Nacional Política: una adhesión que no tenía que consistir en una sublevación, sino en un boicot pasivo de las órdenes de la dictadura ${ }^{55}$. Ésta se presentaba como una condición indispensable para hacer de manera que tal movilización pudiese realizarse pacíficamente, sin causar el comienzo de una nueva guerra civil. Por eso el PCE, en un documento dirigido a las fuerzas de orden público afirmaba:

«Os pedimos que contribuyáis a la lucha del pueblo para poner fin a la dictadura por una vía pacífica [...]. Os pedimos que al tener que ejecutar las órdenes perse-

52 AHPCE, Fondo Documentos, carpeta 41, «Informe del Comité Central. Presentado por el camarada Santiago Carrillo al VI Congreso del Partido Comunista de España. (28-31 de Enero de 1960)», pp.30-33.

53 AHPCE, Fondo Documentos, carpeta 41, «A los comités del Partido. Informe del C. E. del PCE», agosto de 1960, p. 9. En un otro documento se afirmaba: «Numerosos componentes de las fuerzas de Orden Público se sienten mucho más cerca de los obreros y del pueblo que protesta que de los gobernantes corrompidos que saquean el país», en AHPCE, Fondo Documentos, Carpeta 40, «El balance de veinte años de dictadura fascista, las tareas inmediatas de la oposición y el porvenir de la democracia española, Documento del Comité Central del PCE», abril de 1959, p. 79.

54 «Un documento de las C. O. de España a los Ejércitos de Tierra, Mar y Aire», Mundo Obrero, número 20 , noviembre de 1968 , p. 7.

55 «El balance de veinte años de dictadura fascista, las tareas inmediatas...», Ob. cit., p. 79. 
cutorias contra los enemigos de la dictadura, lo hagáis con el máximo de lentitud, sin poner ningún interés en buscar nada que pueda perjudicar a las personas perseguidas y, por el contrario, hagáis por favorecerles en todo lo posible. [...] E Partido Comunista os llama a que en la gran huelga nacional que se avecina, y en su preparación, os conduzcáis como compañeros de los que luchan contra la dictadura y no como sus enemigos, como aliados y defensores del pueblo y no como sostenedores de la dictadura»56.

En realidad todas estas apelaciones nunca encontraron interlocutores dentro de las fuerzas armadas. Esta estrategia de acercamiento, de todas maneras, contribuía a fortalecer su imagen de partido responsable y abierto al diálogo, dando así ulterior profundidad a la Política de Reconciliación Nacional y a su repercusiones en el movimiento obrero.

\section{CONCLUSIONES}

Las jornadas de 1967 habían evidenciado que el PCE consideraba a las Comisiones como al instrumento principal mediante el cual perseguir el objetivo de la Huelga Nacional Pacífica. La participación del nuevo movimiento obrero, en efecto, había permitido a los comunistas poner remedio a algunos problemas que habían determinado el fracaso del jornadismo originario, especialmente al régimen de aislamiento al cual estaban condenados por todos los otros partidos y organizaciones de la oposición. Las movilizaciones de enero y de octubre, además, habían mostrado que el conjunto de las fuerzas antifranquistas se iba enriqueciendo siempre de nuevos elementos, cada uno de los cuales promovía movilizaciones que frecuentemente sobrepasaban los confines de su propio ámbito específico, llegando a conectarse con las iniciativas promovidas por los otros grupos y sectores democráticos. Esto permitió al PCE utilizar a las Comisiones para estrechar lazos con otros movimientos de la oposición, como lo de los estudiantes: factor, esto, que no era imaginable en el 1958 y que en cambio, en el 1967, dejaba imaginar a la posibilidad de una verdadera generalización de la huelga.

$\mathrm{Si}$, como hemos ya dicho, la Huelga Nacional Pacífica nunca se realizó efectivamente, de todas maneras funcionó como «expediente temporal» que el Partido Comunista utilizó en el contexto de la dictadura, porque «descartadas las únicas otras dos posibilidades, la lucha armada o la cesión de la iniciativa a un arreglo monárquico por arriba, no quedaba ningún otro. Si como tal opción no tenía garantizada la posibilidad de llevarse a la práctica, como la historia demostró, sin embargo sí se puede decir que cumplió un cometido de gran trascendencia, el de servir como mito para mantener la movilizaciones en unas condiciones muy difíciles y evitar, así, resignarse al fatalismo ${ }^{57}$.

${ }^{56}$ AHPCE, Fondo Documentos, carpeta 40, «A los miembros del cuerpo de la guardia civil», $y$ «A los miembros de la policía armada".

57 SÁNCHEZ RODRÍGUEZ, J.: Ob. cit., p. 61. 